\title{
"Nunca se falou tanto em informação e nunca se teve tão pouco de informação"
}

\author{
ENTREVISTADA: HAGAR ESPANHA GOMES ${ }^{1}$
}

\section{ENTREVISTADOR: EDSON SEREJO NETO²}

Edson Serejo (ES): Professora Hagar, nos conte como a Biblioteconomia surgiu na sua vida?

Hagar Espanha Gomes (HG): Eu fazia Letras na UFRJ, então teve uma greve de dois meses e eu me desinteressei. 0 professor de latim lia biografias e tinha uma tradução que se chamava estágio, toda semana tinha uma tradução, naquele período da greve era Metamorfoses, de Ovídio, eram uns 15 ou 20 versos para traduzir. E apesar de ter estudado sete anos de latim, no Liceu, sabia muita gramática, mas tradução é difícil, você precisa conhecer bem a estrutura da frase. Um dia, na Biblioteca Pública, fui entregar um livro e uma colega de Liceu, um ano mais velha que eu, tinha entrado na Biblioteconomia e me perguntou: "por que você não faz Biblioteconomia?". Eu atravessei a rua para o Liceu, que tinha minha ficha de ginásio, chorei, implorei, me deram, era o último dia, fiz a inscrição.

ES: Você foi diretora no $\mathrm{IBBD}^{3}$, que é o pré-IBICT${ }^{4}$, de onde surgiu a ideia de criar o curso de Mestrado? Isso partiu de alguma necessidade interna?

HG: 0 IBBD criou um curso de Especialização, acho que uns dois anos depois da sua fundação, em 1954, e Dona Lídia ${ }^{5}$ sempre teve essa ideia de trazer pessoas de outras áreas para trabalhar com informação especializada. Esse curso era aberto a pessoas com qualquer graduação. E havia uma reação muito grande dos bibliotecários, ninguém podia entrar na área, era domínio do bibliotecário.

\footnotetext{
1 A professora Hagar Espanha Gomes é graduada em Biblioteconomia pela Fundação Biblioteca Nacional em 1955, mestre em Ciência da Informação pelo IBBD em 1972 e livre docente pela UFF em 1976.

2 Bibliotecário, Mestre em Biblioteconomia pela Universidade Federal do Estado do Rio de Janeiro.

3 Instituto Brasileiro de Bibliografia e Documentação.

4 Instituto Brasileiro de Informação em Ciência e Tecnologia.

5 Lídia de Queiroz Sambaqui, diretora do IBBD de 1954 a 1965.
} 


\section{Entrevista}

ES: Reserva de mercado.

HG: Sim, reserva de mercado. E depois que criaram o Conselho de Biblioteconomia ficou pior. 0 curso de Especialização, a cada ano, era voltado para uma especialidade e como, ao mesmo tempo, as universidades estavam se estruturando com sistemas de bibliotecas, porque eram bibliotecas isoladas, e havia vários cursos curtos. Em Minas Gerais havia um curso curto, de alguns meses, mas muito bom, e em São Paulo tinha várias iniciativas, eram três ou quatro cursos, e muitas pessoas foram para os EUA fazer Mestrado. Na verdade, o Mestrado não é relevante na estrutura acadêmica americana, mas foram fazer o Mestrado porque era melhor do que os cursos que havia aqui. Então as pessoas que faziam a especialização conosco começaram a ir para o exterior, fazer Mestrado. De modo que falamos: "precisamos abrir o Mestrado aqui também". E as pessoas que fizeram Mestrado depois criaram seus sistemas de biblioteca, foi muito interessante. Minas também já estava pensando em criar um Mestrado, porque já havia enviado muitas pessoas para o exterior, que voltaram com título de doutor. Então, não podíamos ficar de fora, havia chegado a hora, vamos criar um Mestrado! Criamos 0 Mestrado com o apoio do professor Anísio Teixeira. Ele nos deu toda a orientação. Eu estava com Lia Frota, uma colega nossa, mas ele foi de uma simpatia, de uma simplicidade, nos deu toda orientação, e nós prestávamos contas para a universidade de tudo. Se era para contratar um professor, fazíamos relatórios, se tinha seleção, fazíamos relatórios, se tinham resultados, fazíamos relatório, as notas dos alunos, funcionávamos como se fosse um elemento da UFRJ. E tivemos algumas disciplinas lá, inclusive naquela época surgindo a teoria dos conjuntos, estavam ensinando inclusive nas escolas, naquele momento. Então, tivemos o pessoal da Matemática, lógica booleana, porque em 1957, 1958 foi o information retrieval, a booleana, era o momento de fazer buscas. Tivemos toda a base de Matemática nos primeiros anos, e pensamos também em criar um semestre de nivelamento, porque havia gente que não era bibliotecário, a gente começava a falar temas de informação e as pessoas não tinham noção nenhuma, então era preciso um período de nivelamento. Acho que é muito importante, se você recebe pessoas de todas as áreas, ter um período de nivelamento.

ES: Esse ano comemoramos os 50 anos do Mestrado do IBICT. Como foi a vivência de ser 0 primeiro da América Latina? Houve algum desafio especial, pelo tempo que vocês estavam vivendo, 0 tempo histórico, a realidade que vocês viviam?

HG: 0 IBBD era um órgão de aceitação na América Latina. Dona Lídia conseguiu recursos para trazer, por ano, 15 alunos da América Latina prá fazer os cursos de especialização e cada um recebia 
uma bolsa de estudos. Quando abrimos o Mestrado tivemos apoio da Fundação Ford, apoio do British Council, não tínhamos bolsas dessas instituições, mas tínhamos professores de fora. Então a gente já vivia um ambiente diferente. A gente tinha essa preocupação de ensinar teoria da classificação, definir conceitos, temas que são a base da organização do conhecimento, como uma área comum. Não estou falando da Filosofia, nem da Sociologia, somos uma instituição de serviços, o que não quer dizer que não tenhamos teoria, se você não tem uma teoria fica difícil criar um serviço. Fazer um produto é a sua vivência, se você não tem teoria não cria o produto. Há escolas que falam muito em Ciência da Informação, mas quando vamos ver o discurso é só biblioteca. E quando não é biblioteca é Filosofia, Sociologia. Acho importante, mas isso não cria nenhuma cultura crítica na literatura, porque você só tem certeza da teoria quando você testa. Quando você está realizando, está testando, vê o que serve, o que não serve, ajusta o que cabe, o que não cabe. Então, não adianta você só ficar dando aula, se você não for pra o mercado, não for desafiado... Tem pessoas até interessantes, caminhando por áreas interessantes, e acabam indo pra tecnologia, onde o desafio é maior, mas também é mais viável, porque você testa a tecnologia, tendo um software na sua casa ou no seu departamento, você vai usando. Mas construir, produzir alguma coisa, você tem que sair, viver lá fora. Não tem como construir um sistema de informação dentro da sua instituição, demanda muito tempo.

ES: Como vocês conseguiram trazer grandes professores do exterior e como era a relação de vocês, professores brasileiros, com eles? Como era o desempenho deles no curso?

HG: Acho que primeiro foi o peso da instituição, o IBBD, e depois as iniciativas de Dona Lídia e depois da Célia Zaher. Depois com os recursos que tínhamos do British Council e da Fundação Ford, você trazia professores estrangeiros, alguns bem interessantes. E trouxemos, da Case Western Reserve University, onde o professor Jesse Shera era o reitor, que era a universidade americana mais ligada nessa área de information retrieval, tivemos pessoas muito interessantes dos EUA, desse grupo. Outros trouxemos da Inglaterra, porque é onde a Ciência da Informação, a teoria da classificação, é forte. Embora, naquela época, fosse realmente esquema de classificação, o ensino e as aulas, facetado. A gente ainda não tinha aquela ideia de trabalhar a teoria da classificação em outros ambientes, porque isso é coisa recente. Navegação, por exemplo, é tema atual, mas naquela época o que a gente tinha realmente, no Reino Unido, eram as bases da classificação. Mas era a força da instituição. Por que a gente trouxe a Dahlberg? Porque a gente via a literatura da Dahlberg, a gente foi lá no consulado, conversou com os responsáveis e eles pagaram para ela vir. Todas as vezes que ela veio ao curso foi 


\section{Entrevista}

paga pelo Consulado da Alemanha. Eu só não trouxe os russos porque não estou mais na universidade. É transferência de tecnologia.

ES: No curso de Mestrado também havia grandes professores brasileiros, Hilton Japiassú, José Luiz Werneck, Eduardo Silva. Qual a foi a contribuição desses professores para o curso?

HG: Não sei, porque eu já havia saído do Mestrado, fiquei pouco tempo lá. Com a mudança do IBBD para IBICT, fiquei no CNPq. Então, não acompanhei. Mas no tempo que eu estava no Instituto, encontrei muito com eles. Observei que o pesquisador valoriza a informação, é oxigênio para ele, se não tem acesso compromete a produção. Você sabe quando encontra um verdadeiro pesquisador, porque ele valoriza atividade de informação. Vou contar uma história pitoresca. Havia uma engenheira que tinha personalidade forte, quando ela vinha ao IBBD as pessoas da biblioteca se escondiam, porque ela pedia muita coisa. A gente tinha uma biblioteca maravilhosa, a melhor da América Latina, tudo que você precisava estava lá, então ela vinha pedir um turbilhão de coisas e se escondiam dela. Hoje, praticamente, não se frequenta mais a biblioteca, dependemos de informações que estão na internet, na web, mas nem sempre você consegue as coisas que precisa. Acho que o bibliotecário que trabalha na biblioteca precisa ter sensibilidade para se antecipar às necessidades dos pesquisadores.

ES: Conhecer o perfil para poder atuar junto a ele.

HG: E se antecipar, porque um artigo publicado faz parte do passado, você quer que ele saiba 0 que está acontecendo na ciência, atualmente, o que está sendo feito, e é nas reuniões, nos encontros científicos que você vai saber o que tem de mais recente, que você vai trocar informações, frente a frente com as pessoas, com os indivíduos, suas indagações, suas inquietações. Então, essa é uma área importante que a gente incluiu no Mestrado. Tem uma história... estou cometendo algumas indiscrições, mas se eu não falar agora ninguém ficará sabendo. Um dia uma pessoa chegou no CNPq e, conversa daqui, conversa dali, "o que você está fazendo, o que você acha que é importante no curso", e eu estava lendo sobre comunicação, porque o [D.J] Fosket escrevia muito sobre comunicação. Então, pensei, acho que faz falta uma matéria sobre comunicação, e era um pretexto para me chamar prá lecionar.

ES: Foi aí que surgiu a disciplina Comunicação Científica?

HG: Foi. E é muito importante, porque você fica conhecendo os valores, a comunicação direta, a comunicação indireta, é uma parte da sociologia do conhecimento, é muito importante conhecer os 
modelos de comunicação. Tem um livro muito relevante, que a Lena Vânia cita sempre, de um psicólogo (agora esqueci o nome), e ele mostra o poder de comunicação das Ciências Sociais, em que o ápice são os encontros nacionais, e nas ciências hard, em que o ápice são os congressos internacionais. E quanto tempo leva até começar uma pesquisa e ela virar um conhecimento estabelecido em um livro. 0 livro tem o conhecimento já estabelecido, concreto, e o artigo tem as novidades. Então, por exemplo, na nossa área faltam livros. Essas coletâneas, que agora estão na moda, não ajudam muito, é necessário sentar e escrever livros. E acho que é uma construção coletiva. Há pouco tempo eu recebi uma informação de um livro, que deve ter sido elaborado por uns 15 professores, lá da Califórnia. É um trabalho coletivo.

ES: Você é uma admiradora de três grandes nomes de pesquisadores da Ciência da Informação, Ranganathan, Paul Otlet e Ingetraut Dahlberg. Qual a importância desses intelectuais na sua formação? Qual a contribuição desses três autores na Ciência da Informação?

HG: Otlet nem tanto, mas como minha formação é em bibliografia, praticamente não trabalhei em biblioteca. Acho que bibliografia está na origem da Ciência da Informação. 0 que se faz com a bibliografia, se organiza a informação, tradicionalmente não interessa, onde está o documento não interessa, você vai lá no catálogo coletivo e descobre. Hoje não, quando você tem informação ela já está colada na internet, no meio eletrônico, então essa é uma diferença. Mas você organiza a informação em uma espécie de índice no texto integral, então a bibliografia... por isso que eu digo que não tenho experiência de biblioteca e por isso sou muito crítica com os cursos de biblioteconomia, porque acho que a biblioteca mudou, algo tem que ficar, continua sólido, válido, tem o que você abandona e o que é novidade. Tem que fazer esse exercício. E a bibliografia está na raiz, porque trabalha a informação. Otlet trabalhou muito e trouxe a questão da informação. Porque o bibliotecário sempre lidou com isso, com documentos especiais, só que eram documentos especiais ali na biblioteca, então não acredito que ele tenha tido influência tão grande em mim, ele é interessante historicamente. Agora o Ranganathan não, ele não viveu para ver como a teoria dele está na moda.

ES: Organização de websites, busca em multicamada...

HG: Exato. A teoria dele é fantástica. Porque ele era professor de Matemática, na verdade ele trabalhou apenas os conceitos. Ele começa com os princípios normativos, vem em um crescente, até as cinco leis, depois ele dá uma outra lei, da imparcialidade, e diz que se não resolver recorra às cinco 
leis. A resposta na outra lei, se não resolver... é sempre em ordem crescente, se não resolver tem sempre uma lei anterior, um princípio anterior que resolve. A obra dele é pura Matemática. Depois ele começa com os quocientes, se você olhar, estava justamente pensando nisso, na estrutura do curso, primeiro ele começa com coisas que são aparentemente simples, dá os conceitos, o que é entidade, o que é conjunto, o que é conceito e característica, depois diz assim: tem um grupo de alunos, se eu fizer isso não dá certo por causa daquilo, se eu fizer aquilo... Então, vai usando os princípios e vai introduzindo você nos primeiros passos de organizar os grupos, dentro dos grupos a organização, ele fala que você tem um conjunto, a classe é um conjunto organizado, e por aí ele vai colocando a complexidade. E acho que quando ele trabalhou a questão da organização da informação no tempo, que era prá anotação, prá você colocar os livros de norte a sul, leste a oeste ou primavera, verão, outono e inverno Hoje você usa isso em uma arquitetura de informação. Eu estava lendo um livro de arquitetura de informação, de um cara de Brasília, mas não o vi falar em classificação. Você não tem um modelo de navegação se você não tem a classificação, entende? Então, as pessoas ficam falando bonito, cheias de teorias e filosofia, mas isso não vai colocar um sistema em pé. Acredito que a minha influência maior vem pela terminologia, porque quando chegou na questão da recuperação [automática] da informação muitos bibliotecários levaram um susto, tive colegas que choraram, pensavam que a máquina ia fazer tudo. Quem trabalhava com cabeçalho de assunto ficou sem chão, porque cabeçalho de assunto não funcionava mais. 0 que você coloca no lugar? A linha americana é de palavras, e a gente sabia que palavra não resolve. "Transferência de conhecimento", não é a palavra "transferência", nem a palavra "conhecimento", se leem juntas, e aí você vai receber o que você quer. E então eu achei que era alguma coisa de termo, procurei na $\mathrm{ABNT}^{6}$ e achei uma norma de terminologia. Eu não sei se naquela época já havia norma de tesauro, acho que não. Sempre penso em fazer essa pesquisa, mas não vou atravessar lá na ABNT, então fico sem saber. Mas eu imagino, pela época, pelo momento, nos anos 1970, que a gente faz uma comunicação sobre a norma. Quando eu vi a norma, resolveu meu problema. Era uma norma pequenininha, hoje ela está complexa. Isso é outra história para gente contar. Ela era pequenininha, mas resolvia meu problema, porque dizia assim: as relações são lógicas e ônticas... até estava escrito ontológicas, mas uma colega minha disse que o melhor termo é ôntica. Então resolve, porque lógicas são abstratas e ônticas, contiguidade no tempo e no espaço. Então essa foi minha grande influência. E Dahlberg foi um passo adiante, porque ela sistematizou, a gente tinha acesso via Albert, manual de

6 Associação Brasileira de Normas Técnicas. 
terminologia da UNESCO${ }^{7}$, então era através dele. Hoje não, a gente já tem outros instrumentos... Tem uma pesquisadora, Margarete, que descobriu muitas espécies de flores e o pessoal indagava: como ela descobria? Ela dizia: "os livros me chamam”. Uma vez eu estava em uma livraria, que fica lá no $15^{\circ}$ andar, na avenida Rio Branco, Interciência... estava ali em um cantinho, lendo um livro. Hoje mesmo estava lendo esse livro. Um único livro, olha aqui, "Textos escolhidos de terminologia". Uma beleza! Uma porção de gente importante. Os russos também têm muita gente da linguística, mas tudo bem, a gente lê tudo, né? [risos]. E eu descubro esse texto interessante. A Maria Tereza Cabret, que tem muita influência nos bibliotecários brasileiros, que é da área linguística, fez um trabalho maravilhoso.

\section{ES: Textos da escola russa.}

HG: Escola russa. E tem um outro, que é catalão, uma coletânea do Eugene Wüster. Publicada também em espanhol, uma introdução à terminologia. Essa introdução só tem no tablet, no Kindle, mas é um primeiro texto dele, é exatamente a origem da norma, a primeira, hoje a norma está muito sofisticada, muito melhor que as normas de terminologia. Mas quando você lê o texto dele, vê que está seguindo a orientação da norma, a antiga, que levou mais de 10 anos prá ser atualizada. Aí 0 José Rincon ${ }^{8}$ colocou a gente na ABNT, prá gente estabelecer uma base de terminologia, fomos ao congresso em Viena, eu e uma professora, uma colega que trabalhava na ABNT, que era revisora, então tinha cursos de línguas, ela foi fazer o curso de terminologia em Viena, e o Rincón arranjou uma bolsa. Eu falei: não vou, pois já conheço, manda essa menina, que ela vai trabalhar aqui. Então fomos pra Viena e conseguimos aprovar a norma, mudando o conceito de conceito. Brigamos lá, sobre conceito como uma unidade de conhecimento. Quando cheguei no Rio, a comissão havia acabado, então essa norma estava prontinha prá sair, mas não saiu.

Então, eu acho que o Wüster foi importante, aí veio a Dahlberg, também com a teoria do conceito, ela sistematizou, melhorou, teve muita atividade em área de documentação. Inclusive ela fez estágio nos EUA, com um professor que tem nome francês, até pensei que ele fosse francês, mas não. Ela fez estágio com ele. Então ela sempre trabalhou com informação, não é uma bibliotecária, não é uma documentalista, é filósofa, então ela trabalhou conceito. Você faz o conceito que você quer. Você começa a ver os textos de classificação, nas enciclopédias, o conceito, encontrar definição, é disso que eles tratam. 0 que acontece quando você procura esses conceitos nas enciclopédias? Você não

7 Organização das Nações Unidas para a Educação, a Ciência e a Cultura.

8 José Rincon Ferreira foi Diretor do IBICT. 
encontra o que a Ciência da Informação tem, que é uma teoria endógena, que veio da Biblioteconomia, que é a teoria de classificação do Ranganathan. Porque eles trabalham conceito, vão no máximo até onde o Wüster foi, no máximo você vai aos campos semânticos, faz sistema parcial de conceitos, mas dá um modelo para organizar os conceitos de uma certa área, que seriam as categorias. As pessoas não trabalham com as categorias. A Dahlberg trabalha com as categorias, e ela é muito interessante, aquela tabela de classificação que ela criou, a ICC ${ }^{9}$, eu considero como se fosse uma árvore. Então você tem as grandes áreas do conhecimento, dentro das áreas do conhecimento tem um recorte epistemológico, porque a natureza do conhecimento, primeiro teoria e métodos, técnicas, equipamentos e etc., e 0 último é assim, influência de outras áreas na sua área, e influência da sua área nas áreas nos outros. De modo geral, estou explicando, são nove grupos, três, três, três, dessa maneira. Numa página da UFF $^{10}$, a gente tentou colocar isso, para você poder fazer uma revisão de literatura ou para fazer um artigo geral sobre uma área, esse roteiro da Dahlberg funciona. Não funciona prá fazer uma página do meu bairro, mas se for prá uma área do conhecimento, funciona. Ela funciona nesse sentido. Aí, o que ela tem nas pontinhas da árvore, nos galhos, aquele primeiro conjunto, teoria, método, não sei o quê, aí você tem os conceitos ligados à teoria e método, são as folhinhas. A teoria do conceito vai entrar na ponta. Então você tem técnicas, procedimentos, tem toda uma terminologia, todos os conceitos, porque a teoria do conceito serve prá você fazer um trabalho mais científico, ou mais popular, você trabalha com mais rigor ou com menos rigor, dá pra você trabalhar. É uma outra forma de se trabalhar também em um ambiente científico. Então a Dahlberg deu esse avanço, e ela reconhece, quando tomou conhecimento do Ranganathan com as categorias, ela reconhece isso, e você vê que ela tem a lista do Aristóteles, depois tem as categorias dela e depois as categorias do Ranganathan. Naquele texto, na UFF, no final eu reproduzo um quadro dela com essas linhas, que ela segue, ela é aristotélica, animal, depois social, a humanidade, a arte, a filosofia, etc. Então ela trabalha dessa maneira e faz esse quadro comparativo, Aristóteles, a estrutura dela e Ranganathan. Então acho que a Dahlberg é uma influência importante prá gente. E tem o Eugene Wüster, quando ele chamou a área dele de terminologia perdeu um pouco, porque nos anos 1950, pelo que eu tenho lido aqui, vários deles falando dos anos 1950, talvez como uma onda, mas a Alemanha também influenciou nessa área de estruturar a filosofia da linguagem, os linguistas acordaram, porque essa terminologia lembra língua, o termo linguística. Eles tomaram conta e começaram a criticar o Wüster, dizendo que você não pode padronizar a língua. 
Gente, tudo o que bibliotecário faz é padronizar, a gente não vive sem padrão! Agora então, que computador é burro, se você não padronizar, não colocar inteligência nele... Mas os linguistas não conseguem ver isso. "Você não pode padronizar!" Bom, não sei como os linguistas escrevem, mas um físico não usa sinônimos, ele usa aquele termo e é aquele mesmo. Até porque se você usar sinônimo pode dar a ideia que é outro objeto, que está falando de outra coisa. Você tem que ter muito cuidado na comunicação. Acontece que os linguistas não conseguem ver isso. 0 objetivo do linguista é a língua, entende? Então, o Ranganathan era aristotélico, sempre perguntava assim: "é útil aos seus propósitos?". Teleológico, ele diz isso, e o propósito é muito importante, Aristóteles está aí. Então, qual é o propósito do linguista, é a língua; qual é o nosso propósito? Construir uma ferramenta. E eu acho estranho eles dando curso de tradução, não conseguem ver isso, se você não for pro conceito como vai ensinar tradução? A tradução eu acho complexa, porque você tem o vocabulário e tem as expressões, que não têm tradução, é o sentido que você adapta. É o sentido. Então você tem essas expressões, que você tem que dizer isso na outra língua. "Ah, caiu do galho”, como vai dizer isso em alemão? Em francês? Então você tem que adaptar... a adaptação é mais rica, mas tem que trabalhar o vocabulário sistematizado, por que como vai saber que um termo corresponde a outro? Pelo conceito. Você tem o retratinho do cavalo, aí você tem a palavra cavalo aqui e a palavra pferd, então pferd é cavalo em alemão. Então, se não for via conceito, eu não chego lá. Não sei como eles dão curso de tradução na França, mas estão descobrindo o Wüster. Hoje existe um grupo, nesse último texto que fiz, faço um apanhado, um grupo de engenheiros está chamando ontoterminologia e estão trazendo a terminologia do Wüster, ou seja, o conceito, entendeu? E o sistemático, só que ninguém fala no PMEST ${ }^{11}$, a gente tinha que falar um pouco mais desse pessoal, porque você tem um banco de terminologia e tem que organizá-lo em grandes categorias, e eles não têm, no máximo chegam nas classes. Acho que isso é uma contribuição que está faltando, em algum congresso vocês tinham que ir lá e começar a vender esse peixe. Tem algumas atas, que estão disponíveis na internet, se chamam TKE ${ }^{12}$, que é de um grupo francês e alemão, que trabalham muito em conjunto, têm artigos muito interessantes. Agora tem um rapaz chamado Christophe Roche, que está fazendo um movimento para mexer nas normas, para trabalhar toda essa questão da terminologia do ponto de vista onomasiológico, ou seja, começa com conceito depois chega ao termo, e não semasiológico, como os linguistas fazem, que não querem uma

\footnotetext{
11 Categorias fundamentais de Ranganathan: Tempo, Espaço, Energia, Matéria, Personalidade. Fonte: GOMES, H. E., MOTTA, D. F. de, CAMPOS, M. L. de A. Revisitando Ranganathan: a classificação na rede. Disponível em: http://www.conexaorio.com/biti/revisitando/revisitando.htm\#catfund.

12 Technology Knowledge Engineering.
} 
definição, eles querem uma explicação do termo, então no máximo eles fazem um dicionário geral da língua. Já a gente consegue trabalhar com o especialista e ele vai fazer o dicionário especializado, porque é mais fácil a gente passar a teoria prá ele do que a gente aprender o conhecimento dele, que vai fazer um bom dicionário especializado com definições corretas, com definições lógicas, e aí entra a Dahlberg com seu modelo.

ES: Você vai falar a língua dele diretamente.

HG: Então está havendo uma volta ao Wüster, porque ele ficou lá, os linguistas são tão atuantes e começaram a tomar um monte de posições, e todo mundo começou a trabalhar a linguística, mas ela não leva a um produto, uma ferramenta, principalmente por ontologia, onde a definição tem que ser bastante bem estabelecida, porque você vai trabalhar exatamente com essas palavrinhas, influência de, parte de, causa de, essas coisas que o formalismo exige... Você vai colocar em linguagem de máquina para a ontologia funcionar, mas a base, o rigor, você pode pegar da Dahlberg. Se bem que tem o grupo nos países nórdicos, tem o alemão, o Picht, não podia mais fazer a universidade, teve que ir prá guerra, quando ele voltou não tinha mais cidade com universidade, então foi embora pros países nórdicos, onde liderou todo esse movimento. A terminologia é muito desenvolvida nos países nórdicos. A gente tem muito pouca coisa deles em inglês, mas são muito bons. Tem uma que gosto muito, Anita Nuopponen, ela é muito boa, é terminologia, mas ainda não descobriu o que é classificação [risos]. Mas ela é muito boa mesmo, os artigos dela são muito interessantes, e ela tem uma visão bastante ampla, inclusive uma percepção, que a gente tem também, de que com estrutura de terminologia você consegue escrever manuais, ela tem vários modelos, tem uma série de três artigos muito interessantes. Essa linha nórdica do Picht está bastante atuante. Então, você tem a língua alemã, e eles têm acesso à língua alemã, acho que é uma segunda língua, eles têm uma facilidade de acesso. É uma literatura que a gente não tem. Os russos também.

ES: Sabemos que você adora os russos...

HG: Tem um artigo de um encontro, que saiu um livro muito interessante que o IBICT tinha na biblioteca... Eu estava em Brasília e fui à biblioteca e ele não estava lá e ninguém sabia onde estava. Por sorte, quando eu peguei esse livro, todos os textos em inglês, eu copiei, e eu queria copiar os autores em russo, porque se achasse algum resumo interessante eu pagaria para traduzir. Mas não sei, já procurei na internet e também não achei. Um encontro de terminologia nos anos 1970, foi em 
Moscou, e o IBBD tinha na biblioteca, mas na ida pra Brasília acho que o Instituto perdeu muito. Mas talvez eles tenham... A Cecília ${ }^{13}$ é fantástica, tem muita sensibilidade, mas em Brasília você acaba mudando o rumo, acaba sofrendo influência da capital. Também o mundo muda, né?, sem bibliografia e documentação você teria que ter outro papel, mas o IBICT também perdeu liderança, se olharmos os congressos de biblioteconomia, no final tem assim, "recomenda-se ao IBBD que faça isso e aquilo". Nos encontros, hoje, não se vê o IBICT presente, e tem pessoas fantásticas lá, principalmente ligadas à Informática, gente muito boa. Mas o próprio CNPq não valoriza a informação, tem aquelas plataformas que o pessoal de máquina faz, mas que nem sempre é o melhor. Acho que as páginas são horríveis, para você achar a tabela da classificação é difícil, está perdida lá em algum lugar, se acha por acaso. Aquelas tabelas, não se sabe como são feitas, não se sabe como são atualizadas, as pessoas não têm acesso a elas, quando você registra seu documento só tem seu pedacinho, não tem a visão de conjunto. Então, acho que no Brasil as organizações não privilegiam a informação, e acho que a culpa é nossa, nós tínhamos que ser mais agressivos. Tem que estar presente, tem um encontro de engenheiros, você vai lá e fala da sua experiência de organizar aqueles projetos todos.

ES: De onde surgiu a ideia de fazer a tradução do livro Ciência da Informação ou Informática, de A.I. Ghernyi e Alexander Ivanovich Mikhailov, que você editou?

HG: Fui eu mesma. Eu achei que tinha umas coisas interessantes. Mikhailov é muito bom, e ele já é informática mesmo, mas é muito bom, interessante. Eles criaram essa palavra "informática", que é "informação" e "automática".

Quando IBBD virou IBICT havia algumas personalidades que queriam que nossa área se chamasse Informática. Eu briguei muito por Ciência da Informação, e não por Informática, porque senão nós perderíamos a nossa personalidade, seria só máquina. A ANCIB ${ }^{14}$ tem esse defeito... Tem um grupo lá, de Tecnologia da Informação, aí tem coisas que você olha que poderiam estar na Informação, é apenas uma tecnologia, mas hoje você não tem informação se não tiver tecnologia, é cara e coroa. Só com tecnologia você fala do software, mas, e as questões temáticas, as questões sociais? Então, são coisas que poderiam ficar em uma comissão e em outra, porque o princípio de classificação da ANCIB é péssimo. Precisamos de informação médica, mas o que é informação médica? Está trabalhando organização, está trabalhando planejamento, técnicas de informação aplicadas à área médica, o que 
você está trabalhando? E a área é um detalhe. Não tem informação médica, tem teoria da informação, tem terminologia, tem software para organizar isso.

ES: 0 que você está pesquisando agora? Além de estar montando o curso de classificação?

HG: Por enquanto ele está só no pensamento. Já falei com Dilza Motta se ela não quer fazer comigo. Ontem falei com uma menina que está fazendo Mestrado, não tem nada a ver com o Mestrado dela, mas ela é muito curiosa, e perguntei se ela não quer sentar comigo também, para gente fazer um trabalho assim a 10 mãos, 15 mãos. Ver como a gente organizaria esse curso. Um curso a distância, mas um curso fora da academia, com uma plataforma onde você dê aula, dê exercício, cobre exercício dos alunos, de organização da informação, como trabalhar com classes, com facetas, com problemas complicados. Para as pessoas se sentirem seguras para organizar. Porque o mercado está aí, o mercado é esse, organizar informação nas organizações, não é organizar biblioteca.

ES: Estamos chegando ao final e ainda tenho três perguntas para você. A Ciência da Informação tem uma presença forte no Brasil, hoje, isso se traduz em grande número de programas de pósgraduação, mais de 40 periódicos científicos e um grande número de pesquisadores. Como você vê 0 futuro da Ciência da Informação no Brasil?

HG: 0 pessoal faz muito Ciência da Informação para ficar na academia ou para ganhar mais quando se aposentar. Eu acho que uma coisa que não ajuda muito é que as revistas todas são acadêmicas, não tem nenhuma revista independente, ou seja, de repente tem um bibliotecário, profissional bacana em uma empresa, que não tem nem Mestrado, mas que é ótimo, e não tem um lugar para publicar os artigos dele. Tem a literatura americana, o pessoal cita gente que nem é doutor, a maioria não tem doutorado, trabalha na empresa $X$, por exemplo...

ES: São pessoas do mercado.

HG: A gente não tem isso. Então, não tem um espaço para as pessoas trabalharem. A Ciência da Informação fica muito dentro dos muros da universidade e quando sai o pessoal trabalha em biblioteca.

ES: Então, a contribuição prática é pouca? Há pesquisa, a pós, mas não há muita aplicação?

HG: Sim. E quando tem uma pessoa lá fora, pessoas que às vezes não são da área da gente, mas são pessoas que usam a cabeça, usam a lógica e têm coisas interessantes para dizer, mas não tem 
um lugar para elas escreverem, não tem um lugar para elas se encontrarem, o grupo ainda é fechado. As revistas são todas acadêmicas, entende? Tem toda aquela formatação acadêmica, então se você está lá fora não tem espaço, a experiência de fora da academia não aparece. Alguém faz um trabalho na Petrobras e não tem onde publicar, uma revista independente que fale para pessoal de tecnologia informação na empresa, por exemplo. Então, acho difícil a Ciência da Informação sair da academia, ela está muito restrita ao pessoal das universidades, e isso não ajuda muito. Você não consegue ter filhotes.

ES: 0 periódico permanece como o principal canal de compartilhamento de resultado de pesquisa, mas surgem novos espaços de comunicação da informação, como as redes sociais, por exemplo. Como você vê esses novos espaços de comunicação?

HG: Blogs, acho que precisamos de blogs interessantes.

ES: Você acha interessante ter uma política de blogs?

HG: Sim, porque você comunica, toda semana você tem um texto pequeno para escrever, alguma indagação, um aspecto da sua própria dissertação, por exemplo.

ES: Agora a última pergunta. Você é uma professora na acepção da palavra, você tem paixão, demonstra sua paixão em ensinar, sou testemunha disso. E você gosta de falar para a garotada de graduação.

HG: É, eu jamais deixaria a graduação. Jamais.

ES: 0 que você falaria para um aluno hoje?

HG: Nunca se falou tanto em informação e nunca se teve tão pouco de informação. Acho que, no mundo a informação está aí, é organizar e mercado. Uma vez uma colega disse, "ah, você está falando em mercado", e eu vou falar para quem? Tem que dar emprego para essa meninada. Você vai dar emprego onde, em biblioteca pública? 0 país nunca ligou para biblioteca pública. Não é de hoje. A biblioteca do Rio fechou, nem os bibliotecários fizeram movimento, ficou fechada. Então, é porque não é importante. Agora, toda empresa tem alguma coisa para organizar e tem o que dizer para as pessoas. Isso eu falava quando me chamavam para dar uma aula para começar a graduação, "você vai ter oportunidade de emprego", hoje ninguém fala nada, mas você vive naquela necessidade daquela 
instituição, precisa de alguma coisa, mas não fala em informação, fala em gestão, fala não sei o quê, e você diz "eu sei fazer isso, vou lá me aposentar". Não tem a palavra "informação", "documentação", você saca que tem um espaço ali para você organizar para eles. Porque há organização e gestão, você tem gestão da informação, você tem a gestão na empresa, a informação é importante para gestão da empresa, você sabe disso, trabalha em uma empresa onde a informação é valorizada. Então, acho que é mostrar como é o espaço de trabalho que tem aí fora e quais são as bases teóricas, porque tem base teórica...

ES: São deveras importantes para isso...

ES: Você sempre falou isso comigo, tem que se voltar para o mundo, sair um pouco da biblioteca.

ES: Hagar, mais alguma coisa? Posso encerrar aqui?

HG: Sim, pode encerrar. Obrigada! Obrigada pela oportunidade. Eu tenho uma tradução do capítulo do Lancaster que dá essa visão sistêmica, está um pouco desatualizado porque é antigo, mas só na parte de tecnologia, em qualquer lugar que eu vou, mostro essa visão sistêmica, entende? Você tem a entrada de um lado, tem a ferramenta do outro, o usuário do outro, como eles se conectam, como a tecnologia entra, acho que é uma boa começar qualquer aula mostrando onde a sua área entra em um sistema de recuperação de informação. Tenho uma tradução dessas. Adoro traduzir. 